\begin{tabular}{|c|c|}
\hline \multirow{3}{*}{ 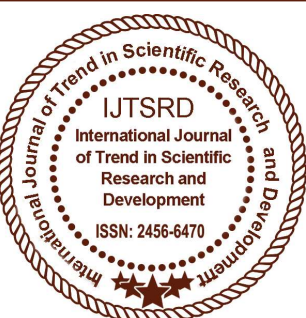 } & $\begin{array}{l}\text { International Journal of Trend in Scientific } \\
\text { Research and Development (IJTSRD) }\end{array}$ \\
\hline & International Open Access Journal \\
\hline & ISSN No: 2456 - 6470 | www.ijtsrd.com | Volume - 2 | Issue -3 \\
\hline
\end{tabular}

\title{
GSM Based Automated Fat Detection and Billing System
}

\author{
Miss. Smita Ganechari, Miss. Sneha Ghode, Miss. Shaheen Choudhari, Prof. Dashavant S. J \\ Department of Electronics and Telecomm Engineering \\ Brahmdevdada Mane Institute of Technology, Solapur, Maharashtra, India
}

\begin{abstract}
India is Farming country. The main source of earning money is farming the side business for farmer is milk collection. This collected milk is given to the dairy industry without any processing. So we are making a system which will going to change the lifestyle of Indian farmer. Dairies collect milk from farmer everyday and payments for this milk are done according to rates per liter. This rate depends on various factors like weight, CLR, SNF of the milk. We develop a system that will measure the fat content in the milk and calculate the payment automatically. And the cost of the milk will send to that farmer via message automatically.[1]
\end{abstract}

Keyword: Aurdino, LASER, LDR, LCD Display, Switches, GSM

\section{INTRODUTION}

The quality of the milk is mainly depend on the Fat content in that milk. So it necessary to measure the fat content in that milk. But the Indian dairies are mainly co-operative. The primary milk provided to the dairy are farmer who do not process their milk and give it in the raw form to the co operative dairy. Since more number of farmers are depositing their milk in dairy. It is daily task of the dairy to access the quality of milk from each farmer, verify it and make the payment based on the quality of the milk.

For measuring the quality of the milk we are mainly using the two sensors LASER and LDR. LASER is a device that emits light through a process of optical amplification based on simulated emission of electromagnenetic radiation. The term LASER

originated as acronym for light amplification by stimulated emission of radiation. The laser is mainly used for measuring the fat content in the milk. The how much amount of light will pass through that milk depending on that intensity we are going to measure the fat content in that milk. For measuring the fat content in that milk we are going to use the LDR i.e. light Dependant Register. The light will pass through the milk and it will capture by the LDR, depending on the LDR light intensity the fat content will measured.

Depending on quality of the milk the cost of that system is decided and that cost is send to that farmer via message.[1]

\section{Motivation for Project:}

As dairy industry is a joint business of farmer, so farmers took more interest in it \& because of this in India more number of Cooperative dairies are formed. Time required for processing this milk is more as after procuring the milk from farmers at village cooperative societies it is then tested for the quality by measuring the FAT content, density of milk \& quantity of milk. As this process is time consuming hence farmers has to stay in a line for an hour or more. Secondly, some milk collection centers do not have the costly milk analyzing equipments so the sample of milk for testing was stored in plastic bottles \& tested only after milk collection process was over, this means that a sample was examine after a one or two hours. This led to unhygienic conditions \& fear of contamination at the center. Since all the measurement is done manually \& the values are also noted manually in farmers membership card hence chances of errors in manual calculation of quality \& quantity by 
cooperative staff. Hence a request from the cooperative staff to reduce above manual work $\&$ to speed up the operation of milk collection, motivate me to develop the Automatic milk analyzing and billing system.[1]

\section{LITERATURE SURVEY:}

The concept of application using Information and Communication Technology (ICT) in the dairy sector was developed by the Centre for Electronics Governance at the Indian Institute of Management, Ahmadabad (CEG-IIMA). The application aims at helping the dairy farmers with timely messages and educating them on the care for their milk cattle and enhances the production of quality milk. It also aims at assisting the dairy unions in effectively scheduling and organizing the veterinary, artificial insemination, cattle feed and other related services. The application uses Personal Computers at the milk collection centres' of the Dairy Cooperative Societies (DCS) having connectivity to an Internet Service Provider (ISP). The application includes two components - a Dairy Portal (DP) and a Dairy Information Services Kiosk (DISK). This paper presents IIMA-CEG's efforts to design and implement the DISK and Dairy Portal.

This Milk Producer Group Resource Book is part of a series of practical field guides for people working in small scale dairying in developing countries. These field guides are produced by the Animal Production and Health Division of the Food and Agriculture Organization (FAO) of the United Nations. Milk producers can increase their income and utilize their skills and resources better if they are working in groups. This book aims to promote the organization of small-scale milk collection and processing as a sustainable, income-generating activity for household food security. It also tries to be a means to improving the safety, quantity and quality of milk and milk products available for consumers in developing countries. The intended readers are (future) leaders of milk producer groups, extension workers, project staff and group promoters who are working to set up milk producer groups, and those developing already existing groups at village level in rural areas. Some excellent FAO booklets exist on working with small groups (see information sources and references). They complement this book which has been written specifically for milk producer groups. This Milk producer group resource book aims to play a role in poverty alleviation in developing countries in a gender sensitive and sustainable way. [2]

\section{PROPOSED SYSTEM:}

The block diagram for proposed system is as shown in the fig. This system eliminates the human involvement from the existing system. The major components used in the system are Arduino, LASER, LDR, LCD Display, GSM and Switches. In this system the LASER and LDR are used as sensor. The laser pass the light through milk and LDR will capture the light, and the fat content will be measured depending on the light intensity as the light is more then fat content is less. As the light intensity is less that means fat content is more.

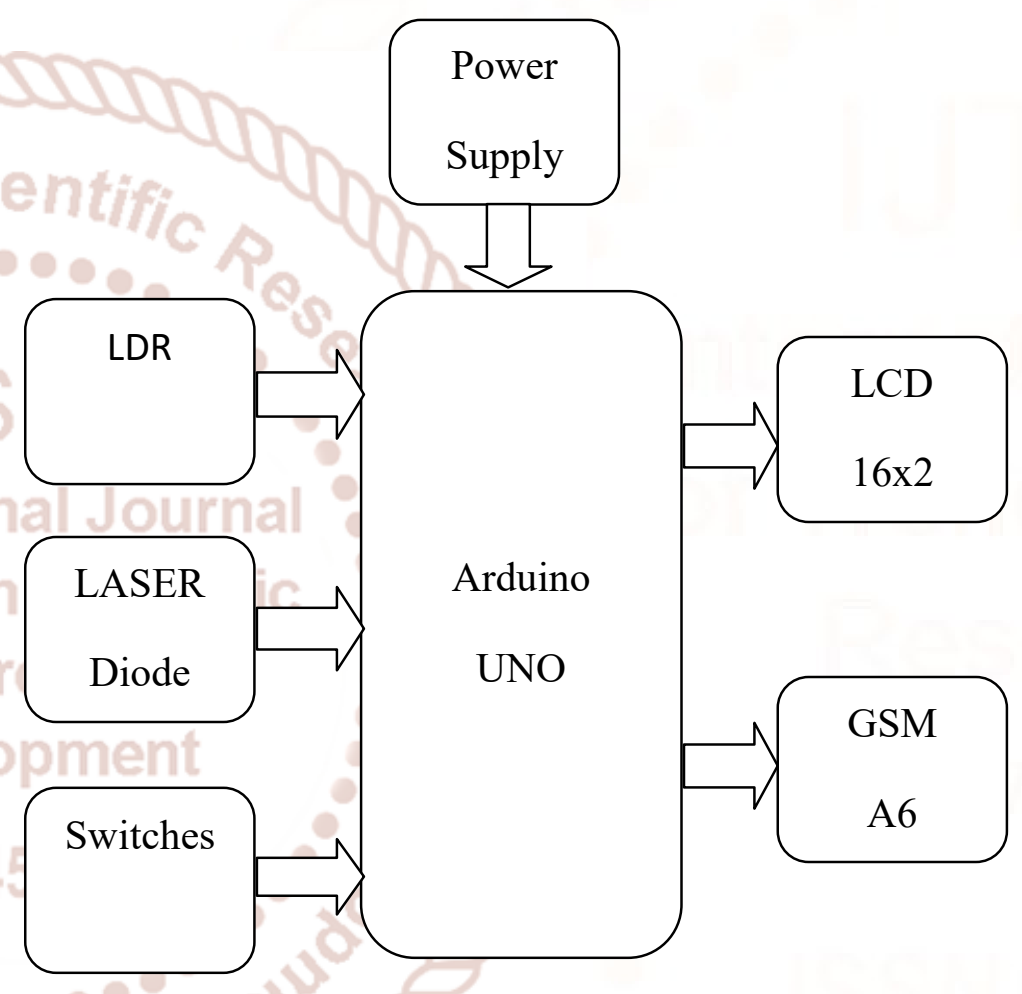

Fig: 1 block diagram of Fat detection \&billing system

In this system we made the one box in that at one end we used the LASER and at other end we used the LDR. In between the LASER and LDR we put the milk sample.

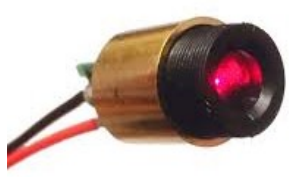

Fig2: LASER Diode

The light will pass through that milk and depending on the light intensity the quality of the milk is decided. 


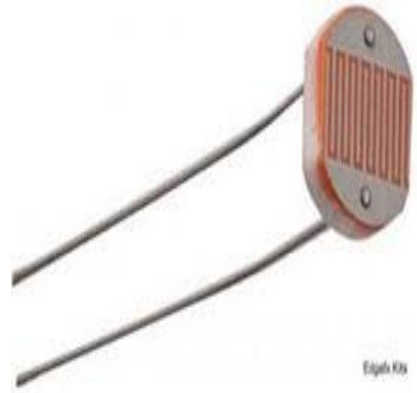

Fig3: LDR

That fat content will be displayed on the LCD Display. As we press the switch the switch then that cost will be displayed on LCD board and that message also be delivered to that farmer.

\section{CONCLUSION:}

The project is good example of the fusion of Biochemical and electronics engineering. The use of Arduino makes possible the calculation of fat content very easy. Because of this system the corruption in dairy system is avoided and errors are not coming in payment calculations. There are different methods available for fat calculation but compare to those systems this system has fast response and cost effective. It reduces the man power. Because of the GSM the cost of the milk is directly display on LCD Display as well as on the farmer mobile via text message.

\section{REFERENCES:}

1) International Journal of Computer Technology and Electronics Engineering (IJCTEE) Volume 2, Issue 2

2) International Journal of Innovative Research in Electrical, Electronics, Instrumentation and Control Engineering ISO 3297:2007 Certified 